\title{
Study of Foot Bath Therapy with Natural Hot Spring Water as a Complementary and Alternative Medicine
}

\author{
Maho Kutsuzawa $^{\mathrm{a}}$, Mayu Kosugi ${ }^{\mathrm{a}}$, Arata Yasuda ${ }^{\mathrm{a}}$, Michiaki Shishido ${ }^{\mathrm{a}}$ * \\ ${ }^{a}$ National Institute of Technology, Tsuruoka College, Sawada104, Inooka,Tsuruoka,997-8511, Japan \\ *Corresponding Author: m-shishido@ tsuruoka-nct.ac.jp
}

\begin{abstract}
Effects of natural foot bath therapy as a complementary and alternative medicine (CAM) was investigated. Components of 3 kinds of natural hot spring water in Shonai region were analyzed via X-ray diffraction (XRD). Yunohama Onsen hot spring water includes much $\mathrm{NaCl}$ than the other water samples. Taking 2 participants to 3 kinds of original natural hot spring and we investigated their electroencephalograph (EEG) and skin condition throughout their taking bath at hot spring. For senior citizens and handicap persons who cannot visit to hot spring facilities, we assumed that home bathing therapy is a very important factor for their mental relaxation. Effect of keeping skin temperature, moisture, elasticity was observed at all original natural hot water, especially, Yunohama Onsen. To compare human body effect between simple hot tap water and brought from original place and warmed Yunohama Onsen Hot spring water for investigating home therapy. Thermograph image shows Yunohama Onsen is better than simple tap water in keeping high skin temperature long period. Skin condition measurements, Yunohama Onsen water proposed higher moisture and elastic condition than simple tap water. These effect is originated from components of hot spring water like Sodium or Calcium Chloride and any interaction between such as components and hot water. In addition, they are formed a layer on the skin which protects drought skin and increase skin elasticity. In this study, the home foot bath therapy with natural hot spring water is expected and effective method for physical handicap parsons, senior citizens as a CAM.
\end{abstract}

Keywords: Complementary and Alternative Medicine, Hot spring therapy, Mental relaxation

\section{Introduction}

Current modern society is "too competitive society" and too managed society", therefore, many people feel stress in their life. Such as mental stress is originated from human-relationship, workplace, sleepless and the others. The stress sometimes causes depression, hyperventilation syndrome, sudden deafness and the other serious illnesses. Therefore, relaxing from such as stress is very important for healthy modern human life. ${ }^{(1)}$

Complementary and alternative medicine (CAM) like hot spring therapy is a trend topic to resolve the such as mental health problems. CAM is defined as "the popular term for health and wellness therapies that have typically not been part of conventional Western medicine." CAM has herbal remedies, aromatherapy, vitamin therapy, and spring therapy. ${ }^{(2-4)}$ In particular, spring therapy is well known popular, effective, simple, and inexpensive method in Japan. In Japan, hot spring are not only ubiquitous all over the country, but also hot spring therapy has long history in Japan. Therefore, analysis of effect of spring therapy is very important and interesting study for both Japanese people and the other country people in future CAM. Particularly, Shonai region is located in north Japan, Yamagata prefecture, has many unique and popular hot spring. Investigation of these spring waters' effect for human health to apply for local region people is important for handicap persons and senior citizens in rural area. In this study, we propose the analysis result of intrinsic component elements of hot spring water and the analysis for the biological effect for human body via foot bath method with some hot spring water in Shonai region 


\section{Experimental}

\subsection{Elements analysis via XRD diffraction}

We prepared three samples of natural hot spring water, i.e., Tsuruoka Ekimae Onsen, Takenokozawa Onsen, and Yunohama Onsen. These sampled hot spring water is dried perfectly with dryer, and the powder samples are analyzed their composition elements with X-ray diffraction (XRD).

\subsection{Foot bath therapy at original natural hot spring bath}

In order to clear the spring therapy effect for human body by natural hot spring water, we propose foot bath method. Two healthy participants ( 2 males, average age 19 years old) visited to hot spring and they were taken the foot bath therapy with these three kinds of natural hot water. For discussing participates relax condition, we investigated state of brain waves, skin temperature and skin condition. The skin condition parameters are moisture condition, oil condition, and skin elasticity. In this experiment, it is under the closed eye situation. Figure 1 shows the time chart of the experiment process. The experiment has three periods, i.e., first period is rest time ( $5 \mathrm{~min}$ ), second period is taking bath time ( $5 \mathrm{~min}$ ), and third period is rest time (5 min). They wearied electroencephalograph (EEG) system on their head, brain wave of participants is measured total 15 minutes, from the start to the end. The skin temperature and skin condition was measured before bathing and after bathing immediately.

EEG brain wave was investigated relaxation condition before bathing, during taking bathing and after. We use "FM-717" equipped biofeedback system as EEG measurements system. Moreover, FM-717 can analyze $\alpha$ wave with equipped software. Generally, the $\theta$ wave $(f \approx$ $5.0 \mathrm{~Hz}$ ) wave shows sleeping or deep meditation, the $\alpha$

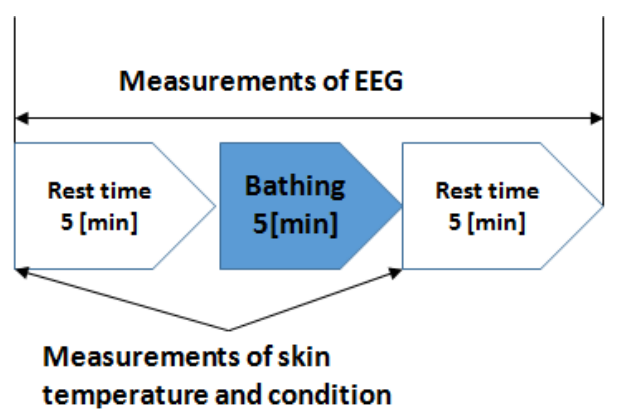

Fig.1 Time chart of the experiment process of foot bath therapy at natural hot spring bath wave is relaxation state, and the $\beta$ wave $(f \approx 22 \mathrm{~Hz})$ is tension or stress state. By the software, it is possible to separate $\alpha$ waves into three kinds of them, i.e., $\alpha 1$ wave (Relaxation: $f \approx 7.5 \mathrm{~Hz}$ ), $\alpha 2$ wave (Relaxation and Concentration: $f \approx 10.0 \mathrm{~Hz}$ ) and $\alpha 3$ wave (Concentration and Tension: $f \approx 12.5 \mathrm{~Hz}$ ). The $\alpha 1$ wave is known the ideal relaxing state.

Skin temperature and skin condition were investigated before bathing and after bathing respectively. To measure the skin temperature, thermograph systems ( $\mathrm{Ti}$ 125, FLUKE) was applied. Image scanning is immediate and can be got a clear image, its resolution is $160 \times 120$. In this experiment, we measure the foot part that is immersed in hot spring water.

Skin moisture meter (TR-3, Sato Shoji) was used to measure skin conditions.

To measure the same position of the foot of the participants each time, marked a point on the instep of them. The skin moisture meter can measure water condition, oil condition, and elasticity at once by setting and input the age of participants. They are evaluated and displayed as a number from 0 to 99 , respectively.

Foot bath therapy at original natural hot spring bath

\subsection{Foot bath therapy at home with natural hot spring water}

For physical handicap person or senior citizens who cannot visit to such as hot spring easily, we proposed potable foot bath therapy with natural hot spring water. As the basic study, we prepared warmed natural hot spring water in our laboratory to take foot bath. For 5 participants (5 males, average age 19.6 years old) were taken two kinds of foot bath, i.e., hot tap water and Yunohama Onsen spring warmed water which is brought from the original spring water. The hot tap water was warmed at $40{ }^{\circ} \mathrm{C}$ to $42^{\circ} \mathrm{C}$, and the hot spring water was warmed at $42.7^{\circ} \mathrm{C}$, it is same temperature with original one. Investigation process is almost same with original foot bath therapy at natural hot spring bath.

Figure 2 shows the time chart of the experiment process. The experiment has three periods, i.e., first period is rest time (5 min), second period is taking bath time (10 min), and third period is rest time $(10+10 \mathrm{~min})$. They wearied EEG system on their head, brain wave of participants is measured total 35 minutes, from the start to the end. ${ }^{(5)}$ The skin temperature and skin condition was measured before bathing and after bathing immediately, 10 min after bathing, and $20 \mathrm{~min}$ after bathing respectively. 


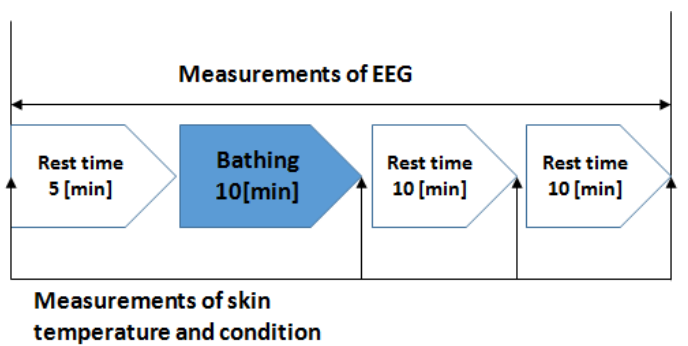

Fig. 2 Time chart of the experiment process of foot bath therapy at home

In this measurements, to investigate brain wave accurately, we analyzed brain wave frequency dependence with fast Fourier transform (FFT) analysis. Moreover, we applied to the measurements with a digital EEG system (EEG-1200 series Neurofax, manufactured by Nihon Kohden). This system can detect weak electric signals from the cerebral cortex via electro-headgear, and signal is amplified and $\mathrm{AD}$ conversion, finally, recorded the data into the PC. Analysis software (EEG Mapping Progra) was used to obtain detailer information from the recorded brain wave data.

In addition, for comparison with skin condition, we measured removed surface moisture agar (konjak) as a bench mark of skin condition. As a result, the water content value of agar was 80.23 and the elasticity value was 30.35 respectively.

\section{Results and Discussion}

\subsection{XRD analysis}

We investigated 3 kinds of hot spring water with XRD analysis, as Table $1 . \mathrm{NaCl}$ is common component in all of water. Tsuruoka Ekimae Onsen includes also $\mathrm{NaHCO}_{3}$, Teakenokozawa Onsen includes also $\mathrm{NaHCO}_{3}, \mathrm{Na}_{2} \mathrm{SO}_{4}$ respectively. Such as components in spring water is still not clear the effect to human body, however, maybe they have any relaxation effect. On the other hands, Yunohama Onsen water includes huge $\mathrm{NaCl}$ rather than the other water samples.

Table.1 Detected component in spring water

Detected components by XRD

Tsuruoka Ekimae Onsen
Takenokozawa Onsen
Yunohama Onsen

$$
\begin{gathered}
\mathrm{NaCl}, \mathrm{NaHCO}_{3} \\
\mathrm{NaCl}, \mathrm{NaHCO}, \mathrm{Na}_{2} \mathrm{SO}_{4} \\
\mathrm{NaCl}
\end{gathered}
$$

\subsection{Foot bath therapy at original natural hot spring}

Table 2 shows the EEG results in foot bath therapy at original natural hot spring bath. In the three original natural hot spring foot bathing, strong consciousness dispersion ( $\alpha$ $2)$, concentration $(\alpha 3)$ and tension $(\beta)$ were detected, so it is not relaxing condition. This results are coursed that the participants were under the noisy environment like public bath space and too short period of bathing. For patents or handicap or senior citizens, quiet and enough long period bath time are important.

In all three hot spring water, the skin temperature was increased after bathing. In particular, Yunohama Onsen water rose body temperature of participants rather than the others. In this results, it is assumed that high $\mathrm{NaCl}$ concentration of water keeps human body temperature.

Figures 3 shows the results of skin condition measurement. In all hot spring water foot bathing, oil condition is not observed varying and it keeps low value. In moisture condition, all measurements indicate increasing after bathing. This results shows that foot bath therapy has effect to increase skin moisture. Only Yunohama Onsen water can increase the skin elasticity. This effect is originated from $\mathrm{NaCl}$ or the other Sodium Chloride systems and Calcium Chloride systems components in the water. ${ }^{(6)}$

Table.2 Detected peaks of brain wave with EGG by foot bath therapy at original natural hot spring

\begin{tabular}{lccc}
\hline \multicolumn{3}{c}{ Detected brain wave [\%] } \\
\hline & Tsuruokaekimae Onsen & Takenokozawa Onsen & Yunohama Onsen \\
\hline Participant A & $\beta: 77.8 \%, \alpha 1: 1.0 \%$ & $\alpha 2: 43.3 \%, \alpha 1: 12.0 \%$ & $\alpha 3: 32.0 \%, \alpha 1: 19.4 \%$ \\
Participant B & $\beta: 60.7 \%, \alpha 1: 0.7 \%$ & $\alpha 2: 36.3 \%, \alpha 1: 21.1 \%$ & $\alpha 2: 38.2 \%, \alpha 1: 9.8 \%$
\end{tabular}


(a) Tsuruoka Ekimae Onsen

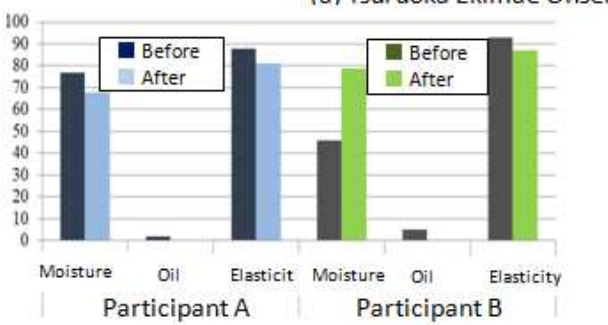

(b) Takenokozawa Onsen

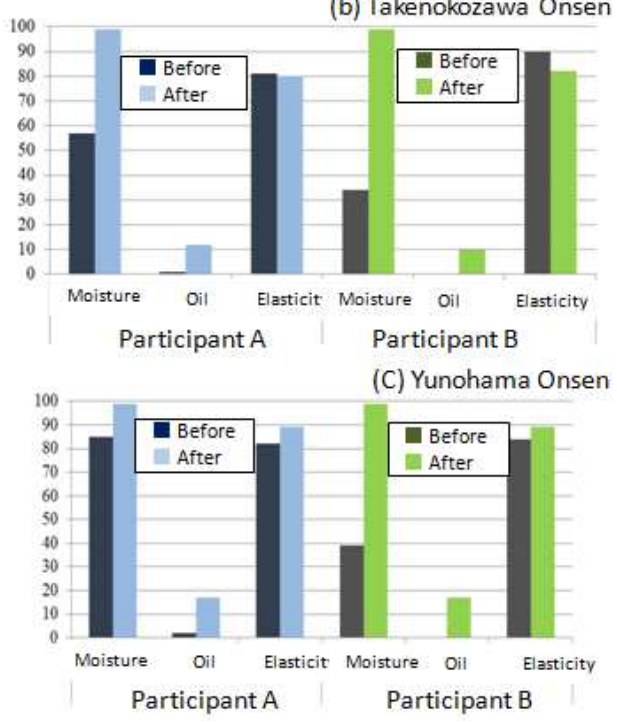

Fig. 3 Comparison of skin condition between before bathing and after bathing; (a) tsuruoka Ekimae Onsen, (b) Takenokozawa Onsen, (c)Yunohama Onsen

\subsection{Foot bath therapy at home with natural hot spring water}

Figure 4 shows brain wave spectra diagram transformed by FFT at bathing time by a participant. Fi.4(a) shows the result of hot tap water bathing, and Fig.4(b) shows results of Yunohama Onsen respectively. The vertical axis indicates intensity of brain wave and the horizontal axis is frequency. There was no so much difference in the results between tap water and hot spring water. Both result show that taking foot bath has relaxation effect because there are continues strong $\alpha 1$ and $\alpha 2$ waves. As time passing, brain status transferred to sleeping mode, i.e., $\theta$ wave region is increased gradually. Because participants were under closed eye mode and relax longtime, their brain switched sleeping mode.
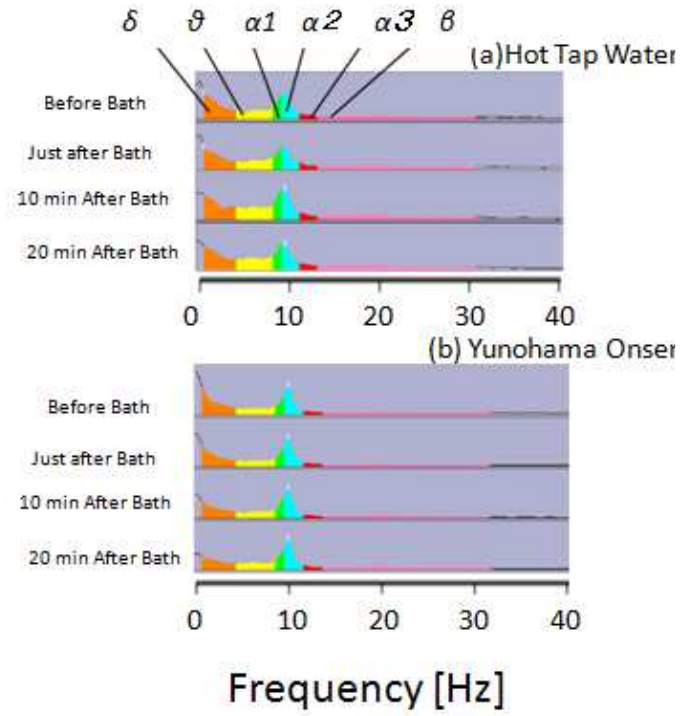

Fig. 4 brain wave spectra diagram transformed by FFT; (a) Hot tap water, (b) Yunohama Onsen

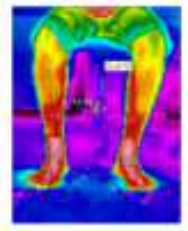

Just After Bath

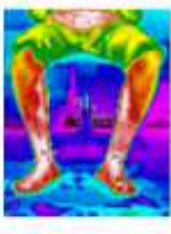

Just After Bath (a) Hot Tap Water

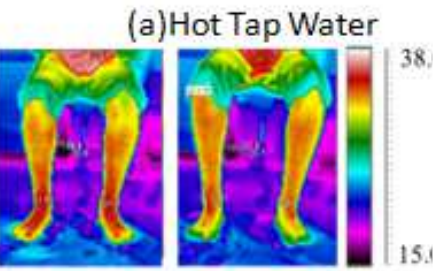

10 min After Bath 20 min After Bath

(b) Yunohama Onsen

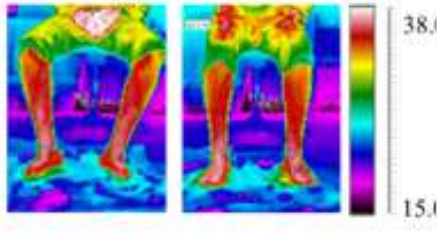

$10 \mathrm{~min}$ After Bath $20 \mathrm{~min}$ After Bath
Fig.5 Skin temperature image of a participant with thermograph system; (a)Tap water, (b) Yunohama Onsen

Figure 5 shows skin temperature image of a participant dependence on passing time with thermograph system. Fig.5(a) is tap water and Fig.5(b) is Yunohama Onsen respectively. Color scale range is from 15.0 to $38.0^{\circ} \mathrm{C}$.

This results shows the hot spring water can keep body temperature longer time than simple hot tap water after bath.

Figure 6 shows that the average skin surface temperature with time transition. Yunohama Onsen spring water can not only keep skin temperature, but also initial warm effect is stronger than simple tap water. In this result, we proposed that Yunohama Onsen hot spring water's warming effect. This effect is assumed to be originated from components of hot spring water like Sodium or Calcium Chloride. 


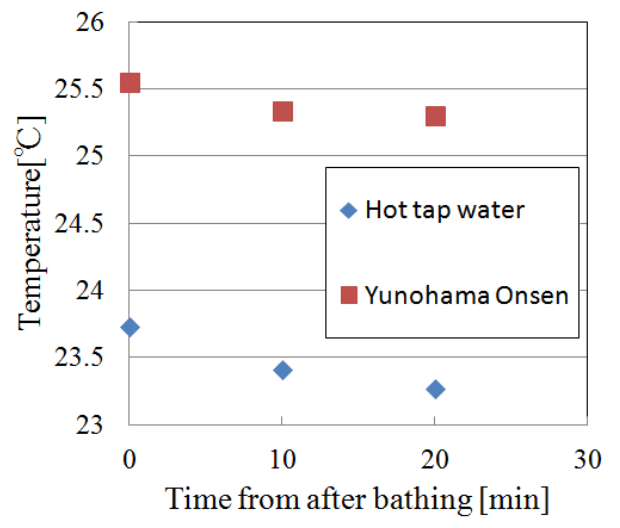

Fig.6 Average skin surface temperature with time transition

Figure 7 shows the comparison of the transition of skin moisture and elasticity condition between hot tap water and Yunohama Onsen. These plots are average of 5 participants. Effect of increasing moisture intensity after bathing is observed in both water, however, Yunohama Onsen spring water has greater. In both condition, moisture intensity is decreased and settled down almost same value before bathing. However, in Yunohama Onsen water bathing can keep moisture condition rather than tap water.

In elasticity condition, almost increasing tendency after bathing were observed in both measurement condition. However, also elasticity condition, Yunohama Onsen water has kept more elastic value.

In a previous work $^{(6)}$, foot baths has thermal effect to whole human body who take the bath. Moreover, on the basis of the results and previous work ${ }^{(6)}$, natural hot spring water includes much minerals and the other components, which form a layer on the skin. Such as layer protects dried skin and increase skin elasticity. Especially, in Yunohama Onsen water includes much $\mathrm{NaCl}$, it is known the forming such as layer. As the other hypothesis, such as minerals and the other hot spring contents varied osmotic pressure or specific heat condition or chemical condition. These effects maybe induced any interaction with hot water like effects of keeping temperature, moisture, and elasticity. As a results, we cleared that Shonai region hot spring water has almost same effect in previous work.

In this research, we proposed that home foot bathing with natural hot spring water is useful and effective for physical handicap parsons, senior citizens as a CAM.

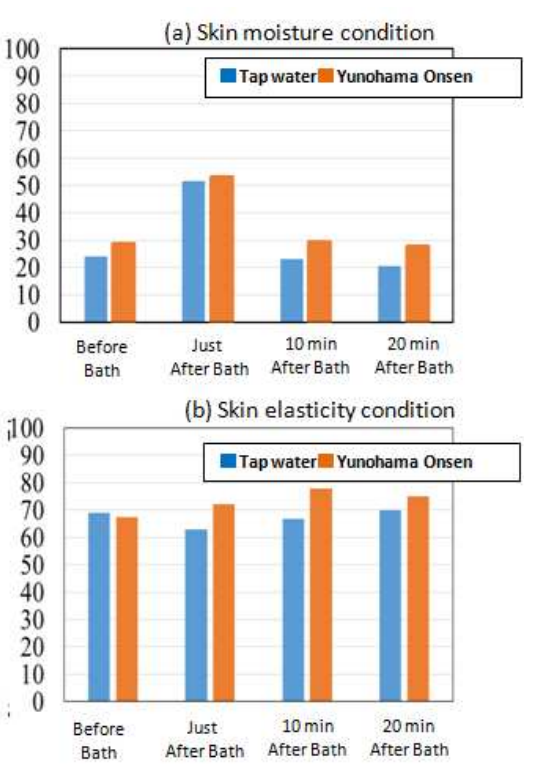

Fig.7 Comparison of the transition of skin condition between hot tap water and Yunohama Onsen; (a) Skin moisture condition, (b)Skin elasticity condition

\section{Summary}

We have investigated effect of natural foot bath therapy as a CAM.

We analyzed components of 3 kinds of natural hot spring water with XRD. Many kinds of elements and compounds were detected. Tsuruoka Ekimae Onsen includes also $\mathrm{NaHCO}_{3}$, Teakenokozawa Onsen includes also $\mathrm{NaHCO}_{3}$, $\mathrm{Na}_{2} \mathrm{SO}_{4}$ respectively. In particular, Yunohama Onsen water includes much $\mathrm{NaCl}$ than the other water samples.

We took participants to 3 kinds of original natural hot spring and we investigated their EEG and skin condition throughout their taking bath at hot spring. From EEG analysis, we observed not only relaxation brain wave but also not relaxation state brain wave. Therefore, home bathing is very important factor for relaxation. Moreover, effect of keeping skin temperature, moisture, elasticity was observed at original natural hot water, especially, Yunohama Onsen. In addition, to clear the effect of home foot bath therapy, we have compared human body effect between simple hot tap water and brought from original place and warmed Yunohama Onsen Hot spring water. On brain wave analysis, we proposed both hot water has relaxation effect. Thermograph image shown Yunohama Onsen is superior to simple tap water in keeping high skin temperature long period. This effect is assumed to be originated from components of hot spring water like 
Sodium or Calcium Chloride. In addition, skin condition measurements, Yunohama Onsen water indicates higher moisture and elastic condition than simple tap water. These hot spring effects are considered that are originated from minerals and the other components. They form a layer on the skin. It is assumed that protects drought skin and increase skin elasticity. In particular, Yunohama Onsen water includes much $\mathrm{NaCl}$, it is known the forming such as layer. Hot water like effects of keeping temperature, moisture, and elasticity. On the basis of this research, we assumed that home foot bath therapy with natural hot spring water is expected and effective for physical handicap parsons, senior citizens as a CAM.

\section{References}

(1) Sugiura-Kokoro-Clinic: http://sugiura-kokoro.com/stress.html, (in Japanese)

(2) Japan Complementary and Alternative Medicine Society: http://www.jcam-net.jp/info/what.html (in Japanese)
(3) Hongbing Wang, Sadanobu Kagamimori, "Review on Japanese articles of Spa's Health promotion effects in past 20 years", The Journal of the Japanese Society of Balneology, Climatology and Physical Medicine, Climatology and Physical Medicine, 69, pp.81-92, 2006 (in Japanese)

(4) Masae Watanabe, Kiyoshi Moriya, Etsuko Kakuta (Yano), Yuko Agishi, "The effect of hot spring bathing on stress reduction, compared with the effect of plain water bathing", Jpn. J. Biometeor., 46, pp.27-34, 2009 (in Japanese)

(5) The Japanese Society of Balneology, Climatology and Physical Medicine: http://www.onki.jp/ (in Japanese)

(6) Noriyuki Tanaka, Kouya Sugimura, Hiroya Shimazaki, Akira Deguchi, "Effects of Hot Footbath on Motor Function in Healthy Volunteer -With special reference for gender difference of foot bath effects-", The Journal of the Japanese Society of Balneology, Climatology and Physical Medicine, 72, 2009, pp.141-147 (in Japanese) 